\title{
ENERGY EFFICIENCY MEASURES FOR AN ELECTRICAL MATERIAL INDUSTRY
}

\author{
LUÍS F. AMADO ${ }^{1}$, HELENA J. MARTO $^{1} \&$ PAULO F. TAVARES ${ }^{1,2,3 *}$ \\ ${ }^{1}$ Coimbra Polytechnic - ISEC, Coimbra, Portugal. \\ 2 INESC Coimbra - Institute for Systems Engineering and Computers at Coimbra, Portugal. \\ ${ }^{3}$ ADAI, LAETA - Association for the Development of Industrial Aerodynamics, Portugal.
}

\begin{abstract}
The main goal of the present paper is to present the study of energy efficiency measures for an electrical material industry. The high-energy consumption of this kind of industry lead companies to search for solutions that allow increasing the energy efficiency in their installations and in the processes, promoting the reduction of the energy consumption and costs. In this context, the objectives of this study emerged, which resulted from the main needs identified by the company. Therefore, the work was divided into four parts. The first one, was the study of replacing the existing lighting (mainly mercury vapor lamps by led); another study conducted was the replacement of the electric motors in injection machines by new and more efficient ones; the third one was the installation of a photovoltaic solar system (for self-consumption) and, finally, the project of a new power converter station for the company. The energy efficiency studies carried out are based on: a careful analysis of the data provided by the company; all the measurements done; the consumption profiles that have been drawn; an extensive market research (with the purpose of finding the most efficient solutions for each case); and in already existing and proven calculation methodologies, leading, in this way, to a greater reliability of the obtained results. These studies showed to which extent the implementation of the various measures presented are economically viable, their impact on the reduction of energy consumption and the annual savings achieved.
\end{abstract}

Keywords: Energy Efficiency; LED Lighting; Induction Motors; Photovoltaic Panels; Power Converter Station.

\section{INTRODUCTION}

It is imperative a responsible energy use, i.e. to consume less energy in each product or service acquired, without changing the lifestyle and/or without sacrificing comfort. This is how the concept of energy efficiency is defined.

Throughout the ages, society has encountered problems both at energy level, with increasing scarcity of fossil fuels, and at environmental level, with the environment degradation, which has dictated the need to reduce energy consumption on a global scale. To reach this goal, each country should create energy policies capable of meeting targets.

At the European Union (EU), in 2008, the European leaders meeting within the Council agreed the triple 20' Energy-Climate legislative package. This package says that member states, by 2020, should: reduce $20 \%$ of greenhouse gases (GHG) emissions compared to 1990 levels, met $20 \%$ of energy needs from renewable sources and reduce energy consumption by $20 \%$ through energy efficiency increase [1].

Currently, there is a new agreement on the Climate and Energy package signed by the 28 member states that sets binding targets for reducing GHG emissions by $40 \%$, compared to 1990 levels, and incorporate, at least, 27\% of renewable energies by 2030 [2]. The compromise reached also includes the indicative target of increasing energy efficiency by, at least, $27 \%$ and $15 \%$ for interconnections between states to ensure that there is a real internal EU energy market [2].

* ORCID: http://orcid.org/0000-0002-3210-3034 
The industrial sector presents a high potential for the implementation of energy efficiency measures, given the large energy consumption that it represents in the global consumption [3]. The measures with the greatest impact on Portuguese industry are, according to [4], the following:

- Electrical motors;

- Heat and cold production;

- Lighting;

- Other measures for increasing the industrial process efficiency.

Considering the various environmental concerns and the possibility of a scarcity of nonrenewable resources in the near future, renewable energy sources have received great attention from companies of the electricity sector and in research and development (R\&D) institutions.

The main objectives of the work presented are four and result from the needs identified by the company at the beginning of this work. They can be summarized as:

- Study of the technical and economic feasibility of replacing existing lighting by 'lightemitting diode' (LED), taking full advantage of existing installations;

- Study of technical and economic feasibility of replacement the existing older electric motors on injection machines by highly efficient motors;

- Study of the technical and economic feasibility of photovoltaic (PV) panels installation to produce electricity to be consumed in the building itself;

- Design of a new Power Converter Station (PCS) with 2500 kVA power, to satisfy the need of expansion of the company's facilities.

\section{METHODOLOGY}

\subsection{Lighting}

Initially, it was performed a survey of all luminaires installed in the plant. This survey allowed a familiarization with the different areas of each plant in order to better understands the needs of each space and what is the solution, which is most suitable for it.

Given the need to find energy-efficient solutions that respect the technical characteristics requested by the company, it was then executed a market search for these solutions.

Using DIALux evo 7 software [5], several luminotechnical studies were carried out to ensure that the solutions adopted did not affect the photometric levels of the existing installation. The software has standard values defined according to current standards; for this case the minimum average values are defined by the European Standard (EN) 12464 - Workplace Lighting.

After validation of lighting performance of the adopted solutions through the luminotechnical studies, a technical and economic evaluation was carried out.

In cost calculation of artificial lighting in each distinct area of the production unit, we used the data collected and some measurements that have been done: survey of installed luminaires, average annual operating hours, estimated average cost of installed technology, power per lighting source and average cost of $\mathrm{kWh}$. The calculations were performed according to the methodology presented in chapter 4.1 of the master thesis [6]. 


\subsection{Three-phase induction motors}

In the initial approach, it was essential to identify the three-phase induction motors (TIM) and to carry out the survey of the information present in the characteristics plates of the electric motors and of a fan of the injection machines.

Because older motors do not have information about their performance recorded in the rating plate, their calculation was made taking into account the data collected.

The market research focused on the TIM premium and super premium, i.e. motors classified according to the IEC 60034-30 Standard in IE 3 and IE 4.

The study of the replacement of existing TIMs by TIM IE3 or IE4 was based on all the technical details collected during the motors inventory, the calculated nominal yields, the rated performance figures for motors similar to the existing ones and for new high performance motors and on the methodology used for the savings and payback calculation.

In order to calculate the profitability of motors replacement, it was performed the calculation of the annual savings resulting from the use of TIM premium/super premium in detriment of the existing TIM. This calculation was done by applying the calculation methodology presented in section 4.2 of [6].

\subsection{Photovoltaic system project}

The interest shown by the industrial sector in the installation of PV systems to reduce energy costs has been increasing. PV production for self-consumption is seen as the solution to reduce dependency on the national electrical grid due to increases in the price of electricity.

In 2016, the International Energy Agency (IEA) report on PV applications trends presented average prices for the installation of industrial PV systems, with a network connection in Portugal in 2015 of $1000 € / \mathrm{kWp}$ in systems with roofs installation and between 700 and $800 € / \mathrm{kWp}$ in systems with ground installation [7].

Considering the studies and reports previously mentioned, it was considered acceptable to assume a cost of $1000 € / \mathrm{kWp}$. This amount already includes the costs inherent to the installation and all the necessary components to the system (without considering taxes).

In the case of use PV systems to sell all the electric energy produced to the grid, the energy produced by the PV system will be remunerated with an auctioned tariff, in which the grid offer the reference tariff of $95 € / \mathrm{MWh}$, valid for 15 years [8].

Another possibility is to consume the totality of the electric energy produced in the plant by the PV system. In this case, we have a PV self-consumption system. This model allows the possibility of selling surplus production to the network at a market rate.

The exploitation of the PV self-consumption system has the advantage of ensuring a part of the consumer's consumption during the period when the price of electricity is the least favorable for the consumer, also reducing the power at the peak hours of the installation, which leads to an even greater reduction in the electrical invoice.

In the design of PV systems, there are several important software programs to assist in the development of feasibility studies of a PV system. 'PVGIS' [9] and 'PVWatts' [10] are software tools available online that generates an estimation of the amounts of electricity produced through a PV system. There are also other software to support the design of a PV system that offer more complete sizing solutions, such as 'Sunny Design' software from SMA Solar Technology AG [11]. For this work, we have mainly used 'Sunny Design' but some relevant data from the other ones was also used when was missing in 'Sunny Design'. 


\subsection{Power converter station project}

In the design of power converter stations it is necessary to keep in mind a set of data and information, as a starting point for the project realization. Therefore, in the embryonic phase of the project, there was a familiarization with the existing PCS, with the equipment present on it and with some parameters of the medium voltage power grid, data obtained from the energy distributor.

In order to construct a PCS that fulfils the objectives that have been proposed while respecting the safety of people and goods, it is necessary to calculate some fundamental electrical quantities, in accordance with the legislation, regulations and recommendations presented in sections 2.4 and 4.4 from [6] and in [12].

\section{CASE STUDY}

\subsection{Company}

The case study is a company that is present in the electric market for more than 40 years, that has about 400 employees distributed by five industrial plants.

The company is placed around $30 \mathrm{~km}$ from Coimbra, which allows fast and efficient dispatch of orders both to the north and to south of the country. There is also a strong focus on internationalization by exporting to more than 50 countries, from Europe to the Middle East and Latin America.

The company develops and manufactures products for low voltage electrical installations, such as soaking, watertight and protruding apparatus, technical gutters, ambient sound, data, voice and image (DVI) and modular apparatus for frames.

\subsection{Electrical energy consumption}

Electricity is the most used form of energy in the company; it is used intensively in various sectors of production and in lighting. However, the contribution of lighting only represents about 10 to $15 \%$ of the total consumption of electric energy.

From the analysis of the 2015 electricity bills, information on monthly and annual energy consumption was obtained, as well as monthly and annual costs with energy and power. Figure 1 shows the monthly evolution regarding consumption and energy charges during the year 2015 .

From the analysis of the diagram of Fig. 2 it was evident that the registered profile coincides with the working hours of the company. During the weekdays, the higher consumption moments occur in the period between 8:00 am and 5:30 p.m., where plants are working in full, with the exception of lunchtime, from 12:30 p.m. to 1 p.m. 30, in which there is a fall in consumption which results into a power reduction in the order of 100 to $150 \mathrm{~kW}$. In the remaining hours, the power registered is in the order of 200 to $300 \mathrm{~kW}$, and is mainly due to the injection sector, which has an independent working schedule: they work during the 24 hours divided in three shifts of $8 \mathrm{~h}$. As for the weekends, there is only an average power of around $30 \mathrm{~kW}$, which may be associated to the existing refrigeration equipment in the kitchen and cafeterias, to the servers, and air conditioning of the rooms where they are, and to the security lighting. 


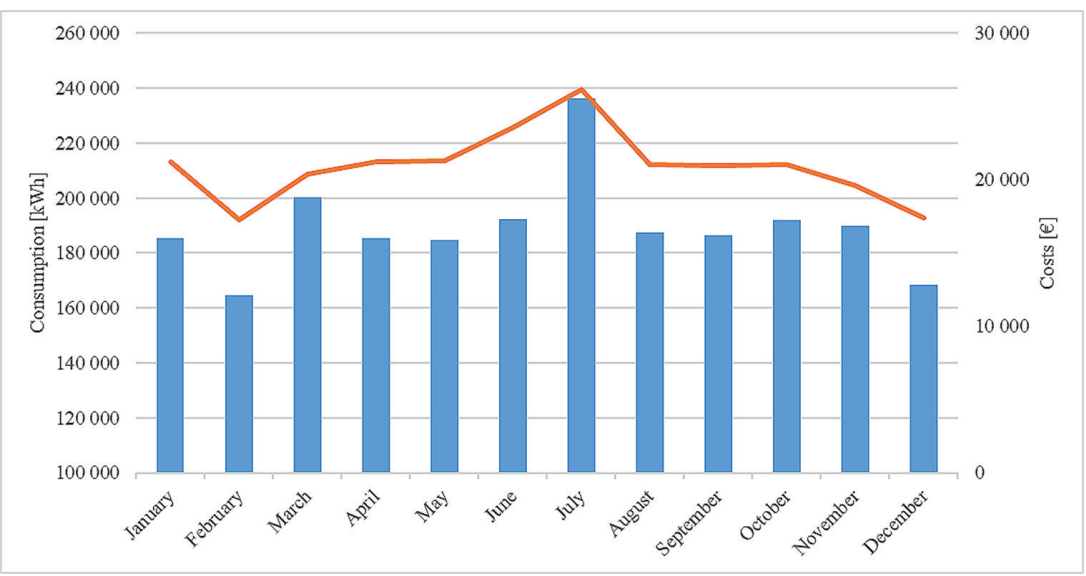

Figure 1: Monthly evolution of consumption and costs of electricity in 2015.

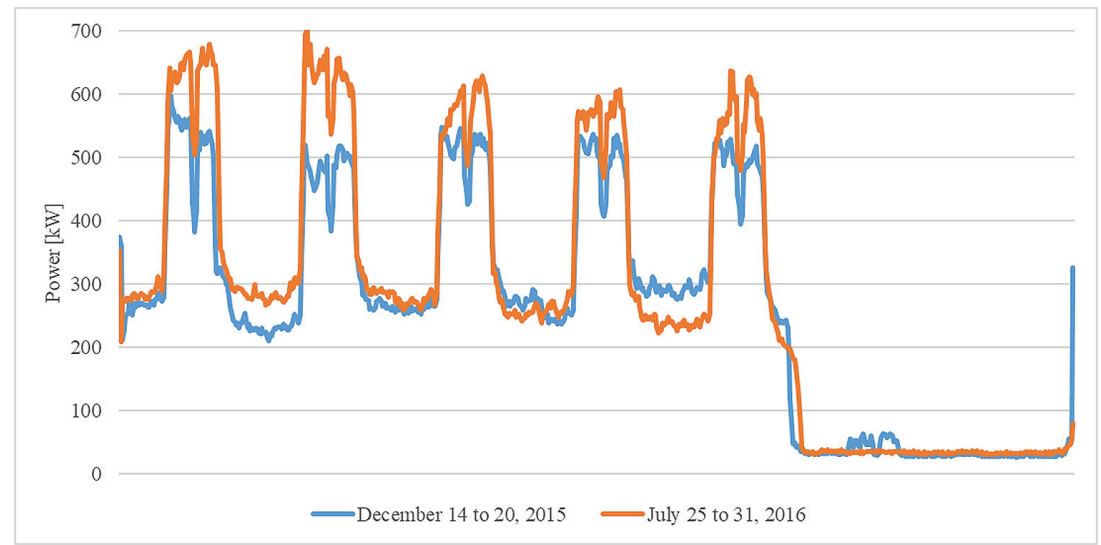

Figure 2: Load diagram for the weeks: from December 14 to 20, 2015 and from July 25 to $31,2016$.

\section{RESULTS AND DISCUSSION}

\subsection{Lighting}

The initial goal was to study the technical and economic feasibility of replacing existing lighting (mainly tubular low-pressure mercury vapor) by LED, taking full advantage of existing facilities for building 2 and production areas. Subsequently, the study was extended to all of the existing lighting. In summary, in terms of substitution proposals, two main scenarios were studied.

Table 1 shows the summary of the economic analysis carried out for each scenario under study.

Scenario 1 contemplates the complete replacement of watertight fluorescent type luminaires by LED luminaires, in building 2 and in remaining productive areas. 


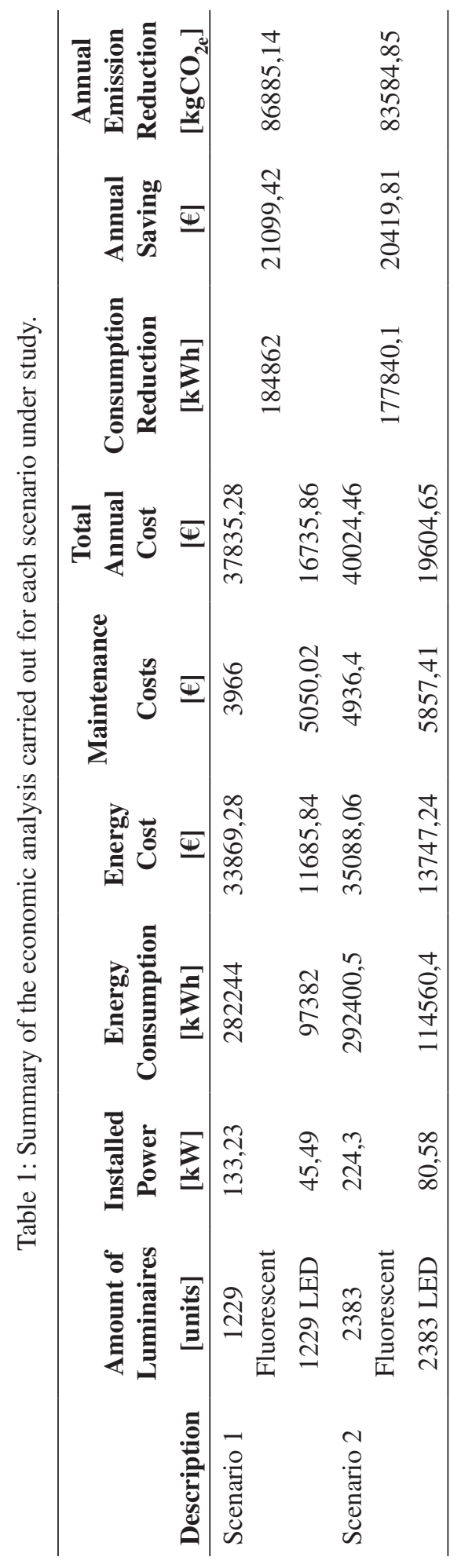


The replacement of watertight fluorescent type luminaires by LED luminaires in this scenario would have an initial investment of $€ 117039$, would bring an annual saving of around $€ 21100$ and the return on investment would occur after approximately 5,5 years.

Scenario 2 contemplates the total replacement of all luminaires by LED. In this scenario, the existing lighting annual consumption is $292400 \mathrm{kWh}$, while the LED solutions present a consumption $114560,4 \mathrm{kWh}$, resulting in a reduction $177840,1 \mathrm{kWh}$. This is because the luminaires that are added to scenario 1 do not present an annual operating time that justifies the investment.

The replacement of the existing lighting by LED is more advantageous in scenario 1 , since it only affects the replacement of luminaires with longer hours of operation. In addition to the economic benefits associated with such substitution, there is also an annual emission reduction of around $86885 \mathrm{kgCO}_{2 \mathrm{e}}$.

\subsection{Three-phase induction motors}

A fact to be retained is that none of these TIMs will operate under full load conditions, so that the calculated performance values for motors in rated load conditions will be difficult to obtain. Therefore, it was important to analyze the applications of the motors and their requirements, in order to better understand the needs in the involved processes. For this, some measurements were made of TIM consumption of some of the injection machines, during a duty cycle.

As an example, one of these load diagrams is shown in Fig. 3. In this case, the load diagram obtained in the TIM of the machine 21 .

Through the analysis of Fig. 3 (where is shown a 24 hours operation cycle of $22 \mathrm{~kW}$ TIM of the machine 21), it can be seen that the motor had a practically constant operation. The average absorbed power was around $9 \mathrm{~kW}$; this value is either still far from the nominal or the rated power absorbed by the motor.

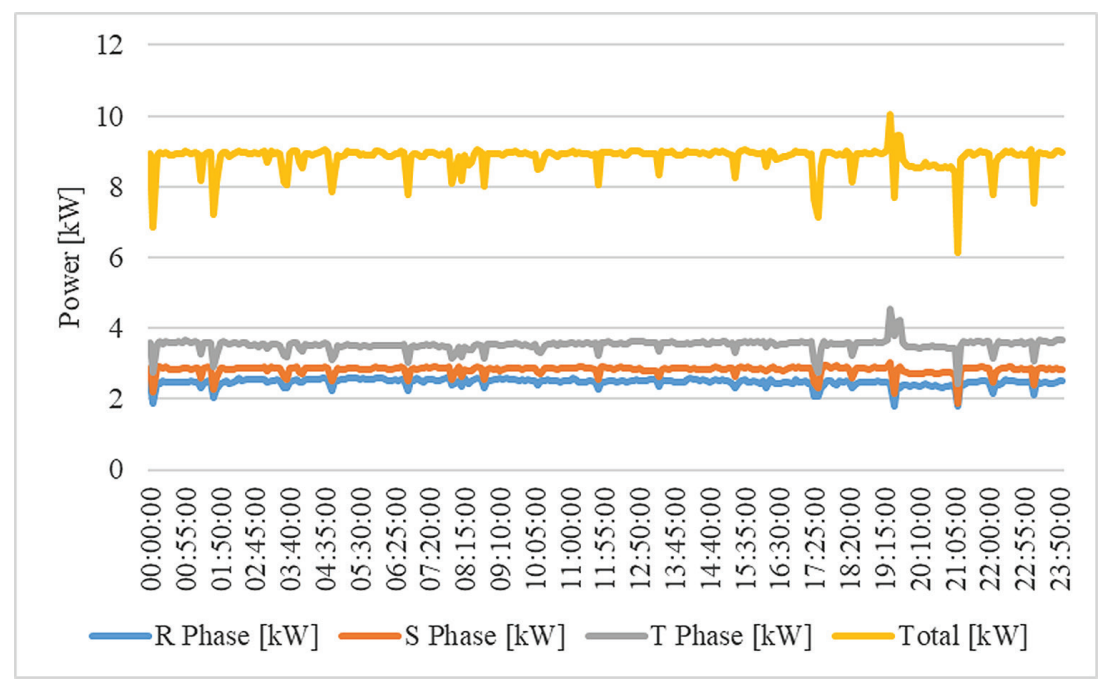

Figure 3: Load diagram obtained at machine 21 TIM; measurement taken on November 23, 2016. 
Table 2: Calculations performed for each TIM under study for the injection machine 21.

\begin{tabular}{|c|c|c|c|c|c|c|c|c|}
\hline \multirow[b]{2}{*}{$\begin{array}{l}\text { Injection } \\
\text { Machine } 21\end{array}$} & \multicolumn{4}{|c|}{ TIM Premium [IE3] } & \multicolumn{4}{|c|}{ TIM Super Premium [IE4] } \\
\hline & $\begin{array}{l}\text { Con- } \\
\text { sumption } \\
\text { Reduction }\end{array}$ & $\begin{array}{l}\mathrm{CO}_{2} \\
\text { Emissions } \\
\text { Reduction }\end{array}$ & $\begin{array}{l}\text { Annual } \\
\text { Savings }\end{array}$ & $\begin{array}{l}\text { Pay- } \\
\text { back }\end{array}$ & $\begin{array}{l}\text { Con- } \\
\text { sumption } \\
\text { Reduction }\end{array}$ & $\begin{array}{l}\mathrm{CO}_{2} \\
\text { Emissions } \\
\text { Reduction }\end{array}$ & $\begin{array}{l}\text { Annual } \\
\text { Savings }\end{array}$ & $\begin{array}{l}\text { Pay- } \\
\text { back }\end{array}$ \\
\hline Load $[\%]$ & {$[\mathrm{kWh}]$} & {$\left[\mathrm{kgCO}_{2 \mathrm{e}}\right]$} & {$[€]$} & [Years] & {$[\mathrm{kWh}]$} & {$\left[\mathrm{kgCO}_{2 \mathrm{e}}\right]$} & {$[€]$} & [Years] \\
\hline 50 & 5023,06 & 2360,84 & 552,54 & 2,30 & 7047,17 & 3312,17 & 775,19 & 1,88 \\
\hline 75 & 3714,11 & 1745,63 & 408,55 & 3,11 & 5567,62 & 2616,78 & 612,44 & 2,38 \\
\hline 100 & 4002,63 & 1881,24 & 440,29 & 2,89 & 5848,25 & 2748,68 & 643,31 & 2,27 \\
\hline IEC IE: 100 & 4636,23 & 2179,03 & 509,99 & 2,49 & 6770,37 & 3182,07 & 744,74 & 1,96 \\
\hline
\end{tabular}

Some identical studies were made for more 12 motors.

From the load diagrams analysis it is concluded that motors are not operating at full load, in most cases they are operating in the 30 to 50\% load range, except for the starting where they usually reach the range of 75 to $100 \%$ charge for a short time.

Considering this, all calculations regarding the replacement of existing TIMs with TIM Premium and Super Premium were made for efficiency of 50, 75 and 100\% of the rated load of the electric motor.

Table 2 shows the practical case application, methodology and assumptions described above, i.e. the TIM replacement of the injection machine 21.

The injection machine 21 practical case is an example of a situation where it is advantageous to replace the TIM equivalent to an existing IE1 by a TIM IE4, as can be seen by calculating the payback in Table 2. In this case, whatever the substitution scenario appears to be profitable, however, the most profitable option is replacement by TIM IE4 for operation at $50 \%$ load.

\subsection{Photovoltaic system project}

In this case study, first, it was made a scenario in which was compared the installation of a PV system with injection in the electrical grid to a PV system for self-consumption. The purpose of this study was to compare the PV system installation for sale all the electric energy produced to the network, with the PV system installation for consumption locally all the energy produced.

It was used Sunny Design software, after setting the necessary parameters in order to guarantee equal conditions for both described situations. After that, it was possible to obtain the estimates regarding the production of electricity, the impact on the consumption of the installation and the associated costs. The comparison of a PV system of $250 \mathrm{kWp}$ in the different models of operation is presented on Table 3 . The analysis of this table permits to conclude that the solution that presents the best results is the PV system for self-consumption.

After the initial approach to the practical case, the scenario of the optimization of a PV system for total consumption of the energy produced was analyzed.

The PV system design for consumption of all the energy produced was 'limited' to a maximum power of $40 \mathrm{~kW}$. This limitation was due to the working schedule of the company, which does not operate during weekends. Energy consumption on these days is residual compared to the values recorded during the days of the week, with all excess production of energy having to be sold to the network. 
Table 3: Profitability of the photovoltaic system, comparing PV system with injection in the electrical grid to a PV system for self-consumption.

\begin{tabular}{lcc}
\hline & \multicolumn{2}{c}{ PV system 250 kWp } \\
\cline { 2 - 3 } Description & $\begin{array}{c}\text { With injection in the } \\
\text { electrical grid }\end{array}$ & Self-consumption \\
\hline Energy production [MWh] & 381 & 381 \\
Grid injection [MWh] & --- & 82,73 \\
Self-consumption [MWh] & 686 & 298 \\
Total profits after 25 years [€] & 8 & 775,93 \\
Payback [years] & & 7 \\
\hline
\end{tabular}

The PV system design for self-consumption with the sale excess production of energy to the grid was limited to not exceed the total contracted power in the installation, that was, at that time, $708 \mathrm{~kW}$.

Figure 4 shows the importance of the production of the PV system in the weekly load diagram.

In general, it was shown that almost all of the total energy produced on weekends had to be injected into the network, due to the reduced consumption recorded since the plant is not in working hours. Another fact to note is that the PV production in the winter months is lower than the production in the summer months. Regarding the design of the PV system, it should be noting that, for the power of $700 \mathrm{kWp}$, in the summer months it is possible that at the time of greatest solar irradiation, PV production exceeds the consumption of the installation, having to inject into the network the excess production of energy.

The optimization of the PV system for self-consumption, besides the impact of the energy production on the consumption of the industrial unit, is also important, to analyze the profitability of the systems. In Table 4, a summary of the studies carried out for the various systems considered is presented.

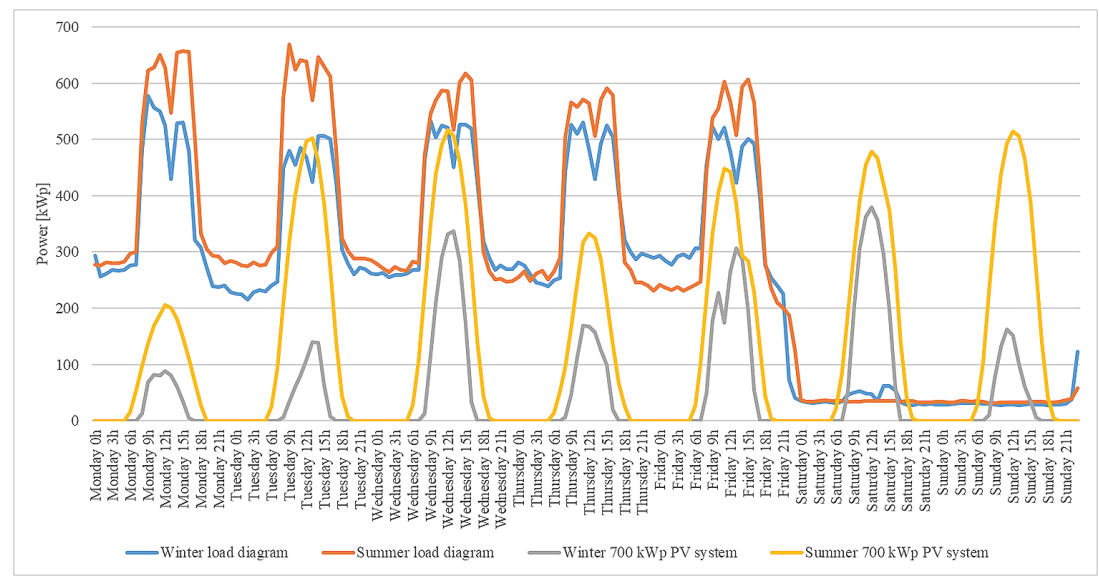

Figure 4: Impact of the production of the $700 \mathrm{kWp}$ photovoltaic system on the weekly load diagram recorded in one winter and one summer month. 
Table 4: Impact of PV system for self-consumption on the reduction of consumption, costs and emissions.

\begin{tabular}{lccccc}
\hline & \multicolumn{5}{c}{ Self-consumption PV system } \\
\cline { 2 - 6 } Description & $\mathbf{4 0 ~ \mathbf { ~ W p }}$ & $\mathbf{3 0 0} \mathbf{~ k W p}$ & $\mathbf{5 0 0} \mathbf{~ k W p}$ & $\mathbf{6 0 0} \mathbf{~ k W p}$ & $\mathbf{7 0 0} \mathbf{~ k W p}$ \\
\hline $\begin{array}{l}\text { Energy production } \\
{[\mathrm{MWh}]}\end{array}$ & 61,046 & 457 & 761 & 913 & 1066 \\
$\begin{array}{l}\text { Grid injection } \\
{[\mathrm{MWh}]}\end{array}$ & 0,259 & 106 & 200 & 253 & 317 \\
$\begin{array}{l}\text { Self-consumption } \\
{[\mathrm{MWh}]}\end{array}$ & 60,787 & 351 & 561 & 661 & 750 \\
$\begin{array}{l}\text { Consumption } \\
\text { reduction [\%] }\end{array}$ & 2,7 & 15,6 & 25 & 29,4 & 33,4 \\
$\begin{array}{l}\text { Cost reduction [\%] } \\
\begin{array}{l}\text { Emissions } \\
\text { reduction [tonCO }\end{array}\end{array}$ & 2,6 & 17,6 & 28,7 & 34,2 & 39,4 \\
\hline
\end{tabular}

\subsection{Power converter station project}

The purpose of this project was to specify the technical conditions of execution and operation of the transformation station whose purpose was to provide low voltage electrical energy.

Given the preference for the construction of an external transformation station, it was decided to use a prefabricated cabin, to be deployed for this purpose.

Three different scenarios were discussed:

1. a new PCS with power of $2500 \mathrm{kVA}$, with only one transformer of $2500 \mathrm{kVA}$, leaving the current PCS deactivated;

2. a new PCS with power of $2500 \mathrm{kVA}$, with two transformers of $1250 \mathrm{kVA}$ in parallel, deactivating the current PCS;

3. a new PCS with power of $1260 \mathrm{kVA}$, with two transformers of $630 \mathrm{kVA}$, connected to the current $1260 \mathrm{kVA}$ PCS.

For each scenario, approach was applied the calculation method mentioned in section 2 of this paper in order to validate each of the proposed solutions. Both scenarios were validated through the calculations made, and the single-wire schematics of the PCS and their respective electrical boards were elaborated.

After that, a search of the existing solutions in the market was made through the contact with the manufacturers and installers of PCS. At this stage, it was found that, although all the solutions under study were validated by the calculations made, only one manufacturer would have available the solution of a PCS with only a $2500 \mathrm{kVA}$ transformer, due to constraints in the placement of a large transformer in a prefabricated cabin; the remaining scenarios were feasible. The final solution choosed was a new PCS with power of $2500 \mathrm{kVA}$, with two transformers of $1250 \mathrm{kVA}$ in parallel, deactivating the current PCS. The schematic for this situation is presented in Fig. 5. 


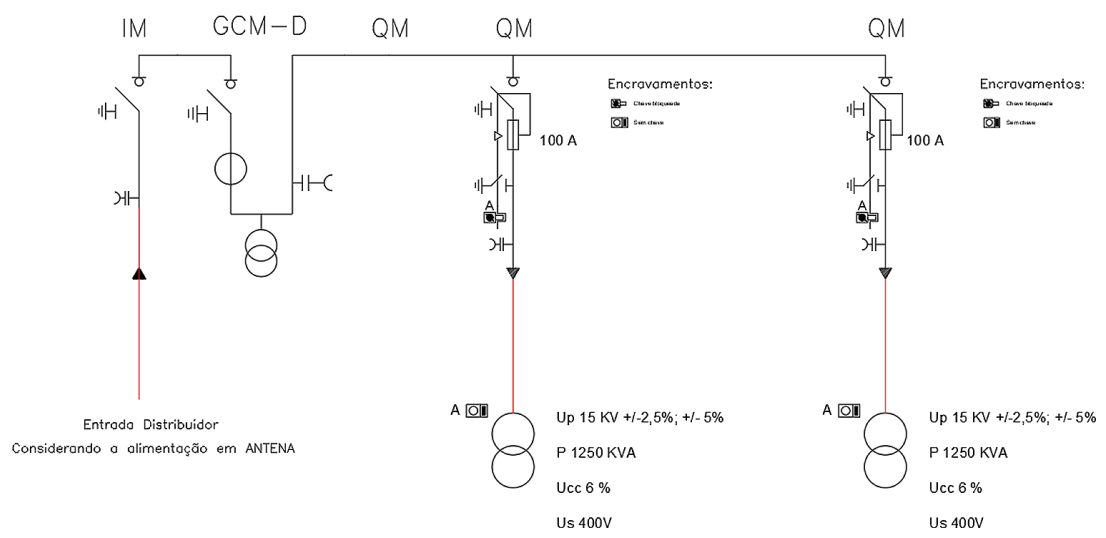

Figure 5: Schematic of the 2500 kVA PCS with two transformers 1250 kVA each one in parallel (in Portuguese).

\section{CONCLUSIONS}

\subsection{Main conclusions}

Lighting was a good investment option, allowing a reduction of around $8,2 \%$ in relation to the consumption of electricity registered in the year 2015. This energy efficiency measure guaranteed a reduction of around $21100 € /$ year with a payback period of approximately 5,5 years.

Regarding the electric motors, through the calculation of the investment return of the replacement of the existing TIM by Premium and Super Premium efficiency TIM, it was found that, in most of the cases studied, motor replacement was cost effective. In situations where replacing the existing TIM with TIM Premium is favorable and if the motor has a reasonable number of hours of operation, replacement by TIM Super Premium is even more advantageous. Although TIM IE4 has a higher cost, around 20 to $25 \%$ compared to TIM IE3, the gains from higher-class motor efficiency coupled with greater TIM operating hour's results into higher annual energy savings and consequently a shorter payback period.

In the implementation of a PV system for own consumption of produced energy, several situations were studied, from a system with $40 \mathrm{kWp}$, with approximately $100 \%$ of selfconsumption, to the limit possible for the company, a system with $700 \mathrm{kWp}$. The systems are optimized according to the company's working hours; in other words, in no case was PV production higher than the consumption recorded during the week. During the whole weekend, the production surplus must be injected into the network.

Table 4 shows the potential for savings and cost reduction that the installation of a PV system for self-consumption can bring to a company. Compared with the other proposed scenarios the installation of a PV system for self-consumption is the one that produces the greatest impact, reducing energy consumption and reducing costs. In industry, solar energy can play a key role in reducing consumption by allowing companies to comply with Portuguese regulations.

The study of the PCS show that after all calculations were made it was possible to validate the three initial scenarios. It was conducted an extensive market research to find commercially available solutions for the scenarios under study. For the scenario involving the acquisition of 
a new PCS with only a $2500 \mathrm{kVA}$ transformer, it was found that only one of the manufacturers contacted would have available a PCS with the requested power that could be placed in a prefabricated cabin. In the remaining situations, the PCS has two transformers in parallel, which makes it possible to have smaller dimensions and thus better integration in prefabricated cabins. The final solution choosed was a new PCS with power of $2500 \mathrm{kVA}$, with two transformers of $1250 \mathrm{kVA}$ in parallel, deactivating the current PCS.

\subsection{Future Work}

Energy efficiency is an area where improvements are always possible. Each passing day, new solutions are emerging in the market with ever higher levels of energy efficiency. There has been a reduction in the price of some energy-efficient solutions, as a result of constant technological innovation, improvement in the manufacturing process and increased competition in the market.

As perspectives of future work, we suggest the following studies:

- Permanent magnet electric motors - at the date of this study, energy-efficient solutions for these kind of motors were not yet available on the market;

- Compressed air - this is a system widely used in industry and, as a rule, has a high-energy consumption, so it is a system where an energy efficiency study will be beneficial;

- Solar water heating system that satisfies the needs of the plant.

\section{ACKNOWLEDGEMENTS}

This work was supported by Coimbra Institute of Engineering - Polytechnic Institute of Coimbra and by projects: UID/MULTI/00308/2019 (supported by the Portuguese 'Fundação para a Ciência e a Tecnologia': FCT - Foundation for Science and Technology) and by the European Regional Development Fund through the COMPETE 2020 Programme, FCT Portuguese Foundation for Science and Technology within project T4ENERTEC (POCI-010145-FEDER-029820).

\section{REFERENCES}

[1] EP seals climate change package, available at http://www.europarl.europa.eu/sides/ getDoc.do?pubRef=-//EP//TEXT+IM-PRESS+20081208BKG44004+0+DOC+XM L+V0//EN, 2008 (accessed 11 November 2016).

[2] Plano Nacional integrado Energia Clima 2030 - Integrated National Plan Energy Climate 2030, available at https://www.portugalenergia.pt/, 2018 (accessed 06 February 2019) (in Portuguese).

[3] Tracking Progress: Industry, available at: https://www.iea.org/etp/tracking2017/industry/, 2017 (accessed on 24 January 2017).

[4] Resolução do Conselho de Ministros n. ${ }^{\circ}$ 20/2013. Diário da República n. ${ }^{\circ} 70$ - I Série. Ministério do Ambiente, Ordenamento do Território e Energia. Available at: https://dre. pt/application/file/260476, (accessed 30 April 2019) (in Portuguese).

[5] DIALux evo 7 software, available at https://www.dial.de/en/dialux/, 2017 (accessed 25 April 2017).

[6] Amado, L., Medidas de Eficiência Energética no Setor Industrial - Measures of Energy Efficiency in the Industrial Sector, MSc Thesis, pp.143, 2018 (in Portuguese).

[7] Internacional Energy Agency, IEA PVPS TRENDS 2016 in Photovoltaic Applications. available at http://www.iea-pvps.org/?id=256; (accessed 30 April 2019). 
[8] Decreto-Lei n. ${ }^{\circ}$ 153/2014. Diário da República n. ${ }^{\circ} 202$ - I Série. Ministério do Ambiente, Ordenamento do Território e Energia. available at https://dre.pt/application/ conteudo/58413591, (accessed 30 April 2019) (in Portuguese).

[9] PVGIS, available at http://re.jrc.ec.europa.eu/pvgis/, 2017 (accessed 30 April 2017).

[10] PVWatts, available at https://pvwatts.nrel.gov/, 2017 (accessed 25 April 2017).

[11] Sunny Design, software from SMA Solar Technology AG. available at https://www. sunnydesignweb.com/sdweb/\#/, 2017 (accessed 25 April 2017).

[12] Ribeiro da Silva, H., Projecto de Postos de Transformação - Project of Transformation Stations (2009-2011). «O Eletricista» journal (in Portuguese). 